\title{
Chapter 7 \\ Trailing and Leading Edge Flaps for Load Alleviation and Structure Control
}

\author{
Vladimir Leble and George N. Barakos
}

\begin{abstract}
This chapter presents the results of numerical computations for a 10MW wind turbine rotor equipped with the trailing and leading edge flaps. The aerodynamic loads on the rotor are computed using the Helicopter Multi-Block flow solver. The method solves the Navier-Stokes equations in integral form using the arbitrary Lagrangian-Eulerian formulation for time-dependent domains with moving boundaries. The trailing edge flap was located at $75 \% \mathrm{R}$, and the leading edge flap was located at $60 \% \mathrm{R}$, where $\mathrm{R}$ is the radius of the blade. The chapter is divided in the description of employed numerical methods, mesh convergence study, and the cases with trailing and leading edge flaps. Also, the chapter defines flap geometry, deformation and frequency of motion. The blade structure was assumed rigid for all presented cases. The comparison of the flap performance is conducted using non-dimensional parameters, and conclusions are drawn at the end of the chapter.
\end{abstract}

\subsection{Numerical Methods}

The HMB3 code is a 3D multi-block structured solver for the 3D Navier-Stokes equations. HMB3 solves the Navier-Stokes equations in integral form using the arbitrary Lagrangian-Eulerian formulation for time-dependent domains with moving boundaries. The solver uses a cell-centred finite volume approach combined with an implicit dual-time method. Osher's upwind scheme (Osher and Chakravarthy 1983 ) is used to resolve the convective fluxes, and MUSCL (Van Leer 1979) variable extrapolation is used to provide formally third-order accuracy on uniform grids. Central differencing (CD) spatial discretisation is used for the viscous terms. The non-linear system of equations that is generated as a result of the linearization is solved by integration in pseudo-time using a first-order backward difference method based on Jameson's pseudo-time integration approach (Jameson 1991). A Generalised Conjugate Gradient (GCG) method is then used (Eisenstat et al. 1983)

\footnotetext{
V. Leble • G.N. Barakos $(\bowtie)$

Division of Aerospace Sciences, School of Engineering, University of Glasgow, James Watt South Building, Glasgow G12 8QQ, UK

e-mail: v.leble.1@research.gla.ac.uk; George.Barakos@glasgow.ac.uk
} 
in conjunction with a Block Incomplete Lower-Upper (BILU) factorisation as a preconditioner. The HMB3 solver has a library of turbulence closures including several one- and two- equation models. Turbulence simulation is also possible using either the Large-Eddy or the Detached-Eddy simulation approach (Spalart et al. 1997). The solver was designed with parallel execution in mind and the MPI library along with a load-balancing algorithm are used to this end. The flow solver can be used in serial or parallel fashion for large-scale problems. Depending on the purposes of the simulations, steady and unsteady wind turbine CFD simulations can be performed in HMB3 using single or full rotor meshes generated using the ICEM-Hexa tool. Rigid or elastic blades can be simulated using static or dynamic computations. HMB3 allows for sliding meshes to simulate rotor-tower interaction (Steijl and Barakos 2008). Alternatively, overset grids can be used (Jarkowski et al. 2013). To account for low-speed flows, the Low-Mach Roe scheme (LM-Roe) developed by (Rieper 2011) is employed for wind turbine cases (Carrión et al. 2013).

The HMB3 CFD solver has so far been validated for several wind turbine cases, including the NREL Annex XX experiments (Gómez-Iradi et al. 2009), where the effect of the blades passing in front of the tower was captured. The pressure and PIV data of the MEXICO project (Carrión et al. 2014) have also been used for validation, where the wake was resolved on a fine mesh capable to capture and preserve the vortices downstream the rotor, which enabled the prediction of the onset of wake instabilities (Carrión et al. 2015).

A new flap deflection algorithm was implemented in HMB3 to allow for arbitrary flap motion. The algorithm is based on the surface interpolation, where the mean, maximum, and minimum flap deflections are defined by separate surfaces. Then, the linear interpolation is employed for each point on the surface between the mean and deflected shape of the flap. The motion of the flap can be a complex function of time i.e. not a simple function like $\sin (\omega t)$ or $\cos (\omega t)$. In this case the motion is described by a Fourier series of arbitrary number of harmonics. It must be noted here, that since only mean and maximum surfaces are known to the solver, the interpolation tends to shrink the flap slightly. To understand this behaviour, consider a 2D rod-like flap shown in Fig. 7.1. As can be seen, the linear interpolation tends to shrink the flap, but the effect is not pronounced for relatively small angles of deflection.

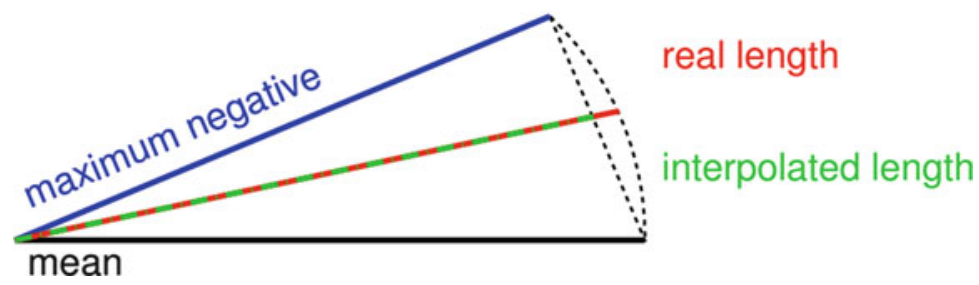

Fig. 7.1 Schematic of the trailing edge flap, showing mean and maximum negative deflections, and real and interpolated length of the flap during motion 
The computational mesh is updated at each time step after the deformation of the surface. The Trans-Finite Interpolation (TFI), described by Dubuc et al. (2000), is applied to the blocks attached to the deformed surface. The TFI interpolates the block face deformation from the edge deformations and then the full block deformation from the deformation of the block faces. The grid deformation uses a weighted approach to interpolate a face/block from the boundary vertices/surfaces respectively. The weight depends on the curvilinear coordinate divided by the length of the curve.

\subsection{Numerical Parameters}

This work employed the DTU 10 MW reference wind turbine design of Bak et al. (2013). For all presented cases, the density of air was assumed to be $\rho=1.225 \mathrm{~kg} / \mathrm{m}^{3}$, the dynamic viscosity of the air was $\mu=1.8 \times 10^{-5} \mathrm{~N} \mathrm{~s} / \mathrm{m}^{2}$, and the speed of sound was $340 \mathrm{~m} / \mathrm{s}$. Further, a fully turbulent flow was assumed with free-stream level of turbulence of $2.6 \%$ and uniform inflow velocity distribution was set across the inflow boundary. The k- $\omega$ SST turbulence model was employed for all tests, unless otherwise stated. The $y^{+}$parameter was estimated based on the flat-plate boundary layer theory. For given Reynolds number, inflow velocity $\mathrm{U}_{\infty}$, density $\rho$, dynamic viscosity $\mu$ and cord length $\mathrm{c}$ the $y^{+}$parameter was computed in the following steps:

1 Estimate the skin friction coefficient from Schlichting's correlation:

$$
C_{f}=\left[2 \cdot \log _{10}(R e)-0.65\right]^{-2.3}
$$

2 Obtain the wall shear stress from the definition of $\mathrm{C}_{\mathrm{f}}$ :

$$
\tau_{w}=C_{f} \cdot 0.5 \cdot \rho \cdot U_{\infty}^{2}
$$

3 Compute the friction velocity from:

$$
U_{*}=\sqrt{\tau_{w} / \rho}
$$

4 Compute the $y^{+}$parameter from the definition, where y is the employed spacing next to the wall:

$$
y+=y \cdot \rho \cdot U_{*} / \mu
$$

For the presented cases with trailing and leading edge flaps, the inflow wind speed was set to $11.4 \mathrm{~m} / \mathrm{s}$, and the rotational speed of the rotor was set to $9.6 \mathrm{rpm}$, giving a tip speed ratio of 7.83 . 


\subsection{Mesh Convergence Study}

The mesh convergence study was performed before various test cases were computed to find the required density of the mesh and cell distribution in the vicinity of the blade surface. Only $70 \%$ of the blade was modelled for this study-from $0.3 R$ to $1 R$, where $R$ is the radius of the blade. The flow around the blade was considered to be periodic in space and time. This allowed the use of the HMB3 "hover" formulation described by Steijl et al. (2006). The formulation includes a combination of mesh motion and additional source terms in the Navier-Stokes equations. The spinner was approximated with a long cylinder running parallel to the flow along the computational domain. The free-stream was kept to the level of turbulence of $2.6 \%$, and the $\mathrm{k}-\omega$ turbulence model was employed. The conditions selected for the mesh convergence study are presented in Table 7.1. The domain size and boundaries are shown in Fig. 7.2, and the results of the mesh convergence study are presented in Fig. 7.3. This study showed that a mesh density between 3 and $5 \mathrm{M}$ cells per blade is sufficient to obtain mesh independent solutions.

Table 7.1 Computational conditions for the mesh convergence study

\begin{tabular}{l|l}
\hline Parameter & Value \\
\hline $\mathrm{U}_{\text {wind }}$ & $11 \mathrm{~m} / \mathrm{s}$ \\
\hline $\mathrm{U}_{\text {tip }}$ & $82.437 \mathrm{~m} / \mathrm{s}$ \\
\hline $\mathrm{RPM}$ & 8.836 \\
\hline $\mathrm{Re}_{\text {tip }}$ & $34.817^{\circ} \times{ }^{\circ} 10^{6}$ \\
\hline $\mathrm{M}_{\text {tip }}=\mathrm{U}_{\text {tip }} / \mathrm{U}_{\text {sound }}$ & 0.243 \\
\hline$\lambda$ & 7.494 \\
\hline Pitch angle & $0^{\circ}$ \\
\hline
\end{tabular}

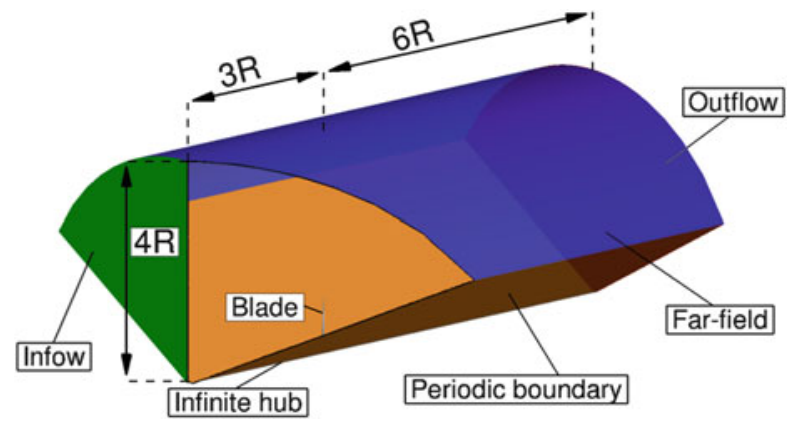

Fig. 7.2 Computational domain for mesh convergence study with employed boundary conditions. Part of the domain removed to expose the blade 

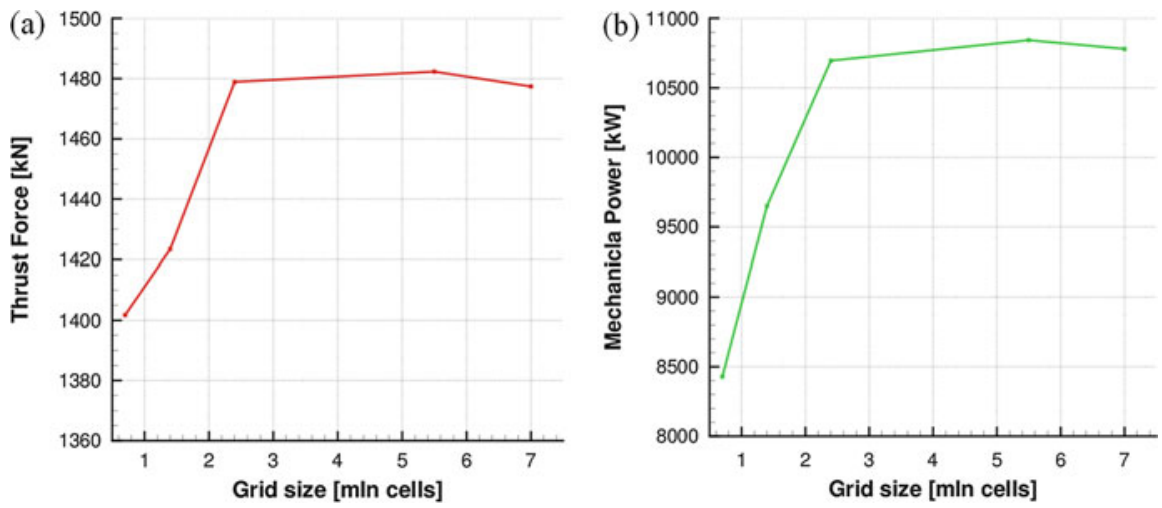

Fig. 7.3 Thrust force (a) and mechanical power (b) as function of computational grid density

(a)

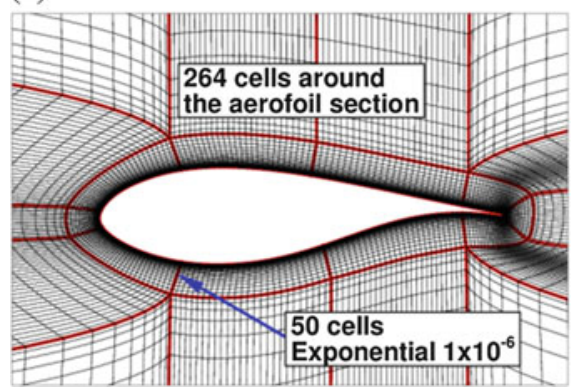

(b)

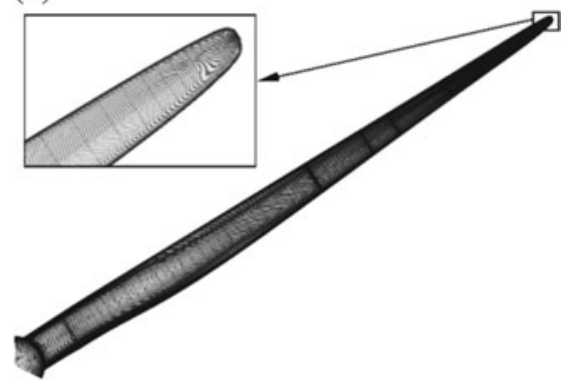

Fig. 7.4 Slices through the mesh near the surface of the blade (a); and surface grids (b) for the $9.2 \mathrm{M}$ cell grid

\subsection{Computational Grid}

Based on the mesh study, a fine mesh consisting of $9.2 \mathrm{M}$ points was constructed and included the necessary refinement to allow for the flaps. The computational domain had the same dimensions as for the grid convergence study shown in Fig. 7.2. The grid included the complete DTU 10 MW RWT blade in a straight configuration (no pre-bending or pre-coning), and employed an O-grid topology around the aerofoil sections, as shown in Fig. 7.4a. The first cell wall distance was $10^{-6} c$, where $c=6.206 \mathrm{~m}$ is a maximum chord of the blade. The $y^{+}$parameter for this gird at rated conditions was 0.2 . Figure $7.4 \mathrm{~b}$ shows the surface grid on the blade for the 9.2 M cells grid.

The blade was modelled in a straight configuration with a simplified nacelle, as shown in Fig. 7.5. The simplified nacelle shape was obtained by rotating the hub of the rotor by $180^{\circ}$. 


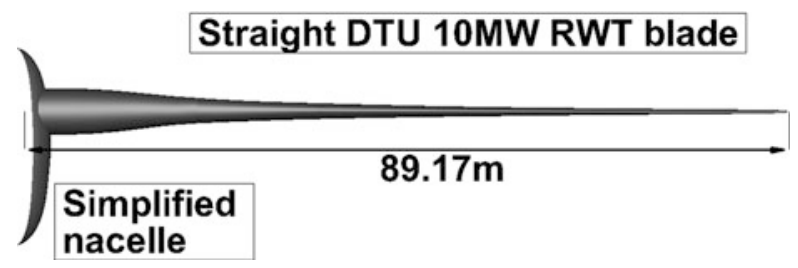

Fig. 7.5 Shape of the DTU 10 MW RWT blade with simplified nacelle as employed for the $9.2 \mathrm{M}$ cells mesh

(a)

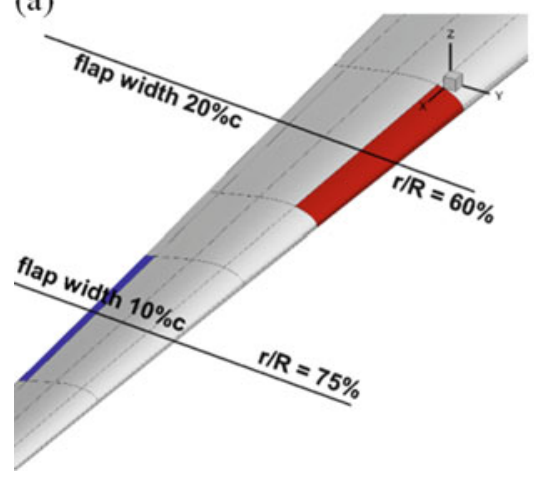

(b)

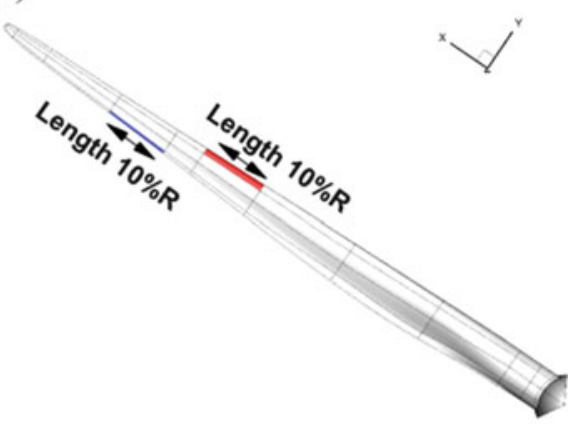

Fig. 7.6 The location and dimensions of the trailing and leading edge flaps. (a) Location and width of the flaps. (b) Length of the flaps

\subsection{Definition of the Flaps}

The DTU 10-MW RWT blade was equipped with leading and trailing edge flaps. The leading edge (LE) flap was located at $60 \% \mathrm{R}$ station, and the trailing edge (TE) flap was located at $75 \% \mathrm{R}$. The length of each flap was $10 \% \mathrm{R}$, but the width of the TE flap was $10 \%$ of the local chord, whereas the width of the LE flap was $20 \%$ of the local chord, as shown in Fig. 7.6a, b. The choice of the TE flap width was made under the understanding that flaps will be used for load control and elevation. For the LE flap, it was assumed that its operation is similar but less efficient to that of the TE flap. The width in this case is increased to $20 \%$ so as to allow larger control surface and a smooth transition of the surface slope.

The deformation of the flaps was defined with respect to the mean line of the aerofoils as indicated in Fig. 7.7. The deformation of the mean line was defined by the shape function $\eta(\xi)=\alpha \xi^{2}(3-\xi) / 2$, where $\xi \in[0,1]$ and depends on the location of the deformed point $x$, and $\alpha$ is providing the maximum deflection for given time instance. For the trailing edge flap $\xi^{T E}=\left(x / c-x_{0}^{T E}\right) /\left(1-x_{0}^{T E}\right)$, and for the leading edge flap $\xi^{L E}=\left(x_{0}^{L E}-x / c\right) /\left(x_{0}^{L E}\right)$, where $x_{0}^{T E}$ and $x_{0}^{L E}$ are the $x / c$ locations of the hinge point for the trailing and leading edge flap, respectively; and 
(a) $\xi=\left(x_{0}-x\right) / x_{0}$

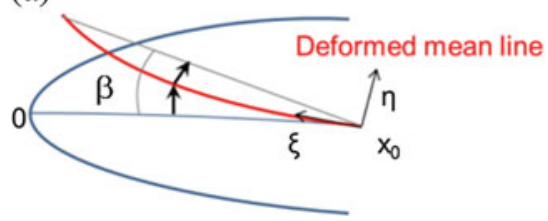

(b) $\quad \xi=\left(\mathrm{X}-\mathrm{X}_{0}\right) /\left(\mathrm{X}_{\mathrm{TE}}-\mathrm{X}_{0}\right)$

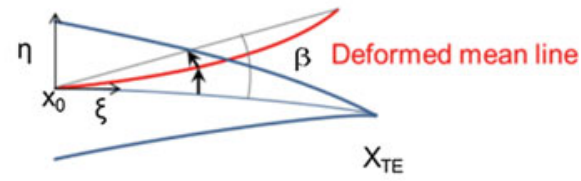

Fig. 7.7 Definition conditions for the LE (a) and TE (b) flap deformation

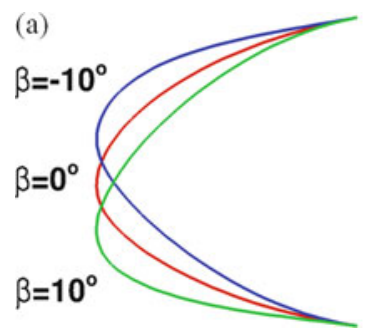

(b)

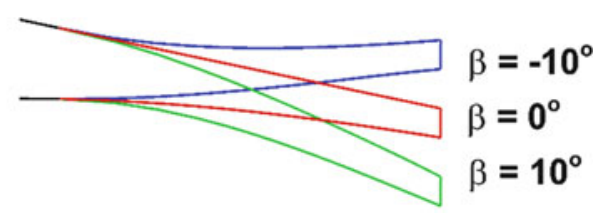

Fig. 7.8 Definition of the positive and negative deflection for the LE (a) and TE (b) flap

$c$ is the local chord. From the equation for the shape function it follow that $\eta(\xi) \in$ $[0, \alpha]$. In principle, $\alpha \equiv \alpha(t)=\alpha_{m} \sin (\omega t)$, where $\alpha_{m}$. is the maximum value of deflection determined by the maximum deflection angle $\beta$. Here, the maximum deflection was obtained as $\alpha_{m}^{T E}=\left(1-x_{0}^{T E}\right) \tan (\beta)$ and $\alpha_{m}^{L E}=\left(x_{0}^{L E}\right) \tan (\beta)$ for trailing and leading edge flap, respectively. By denoting the point at which the flap starts with $x_{0}$, the process to compute flap deflection is as follows: For each point $x>x_{0}$, define $\xi=\xi(x)$ based on the length along the chord line; compute point displacement $\alpha$ based on the maximum deflection angle $\beta$ and time $t$; compute shape function $\eta(\xi)$; apply shape function and obtain deformed flap shape.

The flaps were deflected form $-10^{\circ}$ to $10^{\circ}$ with the shape and notation presented in Fig. 7.8. The frequency of flap motion was set to $0.96 \mathrm{~Hz}$, or six times per revolution.

\subsection{Results for the TE Flap}

Span-wise load distributions for the DTU 10-MW reference wind turbine equipped with the trailing edge flap are shown in Fig. 7.9. The Flap oscillates at frequency $0.96 \mathrm{~Hz}$ - six times per revolution. The length of each section in radial direction used in pressure integration is $\Delta r=2.15 \mathrm{~m}$. 

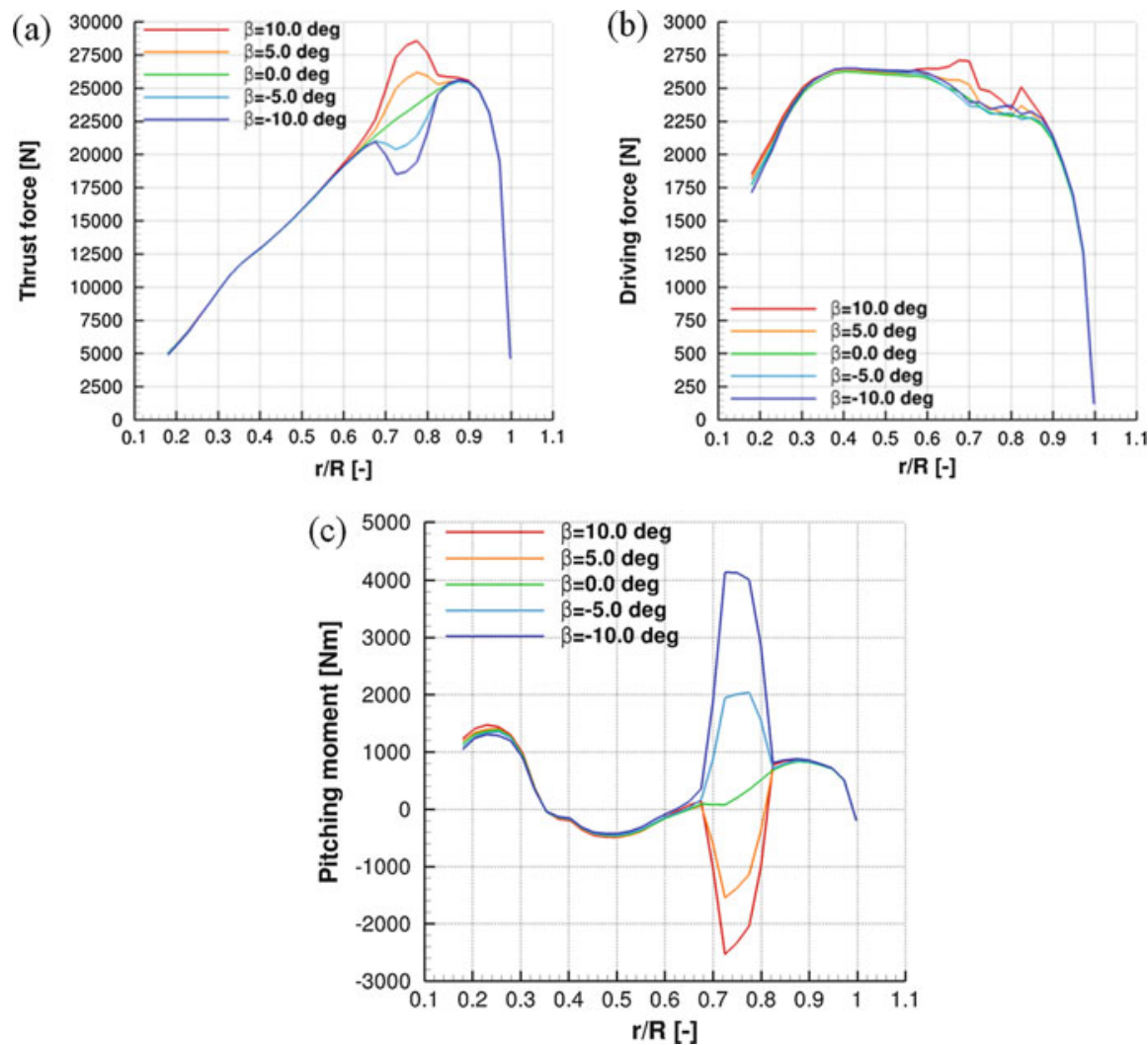

Fig. 7.9 Spanwise distribution of thrust force (a), driving force (b) and pitching moment (c) for DTU blade equipped with TE flap. Flap motion frequency $\mathrm{f}=0.96 \mathrm{~Hz}$ (6 times per revolution)

\subsection{Results for the LE Flap}

Span-wise load distributions for the DTU 10-MW reference wind turbine equipped with the leading edge flap are shown in Fig. 7.10. Flap oscillates at frequency $0.96 \mathrm{~Hz}$ - six times per revolution. The length of each section in radial direction used in pressure integration is $\Delta r=2.15 \mathrm{~m}$.

\subsection{Comparison of the Performance}

In order to conduct a meaningful comparison of the performance of both flaps the non-dimensional coefficients were used. This was chosen, since flaps are located at different radial positions and have different inflow conditions. For this, the normal 

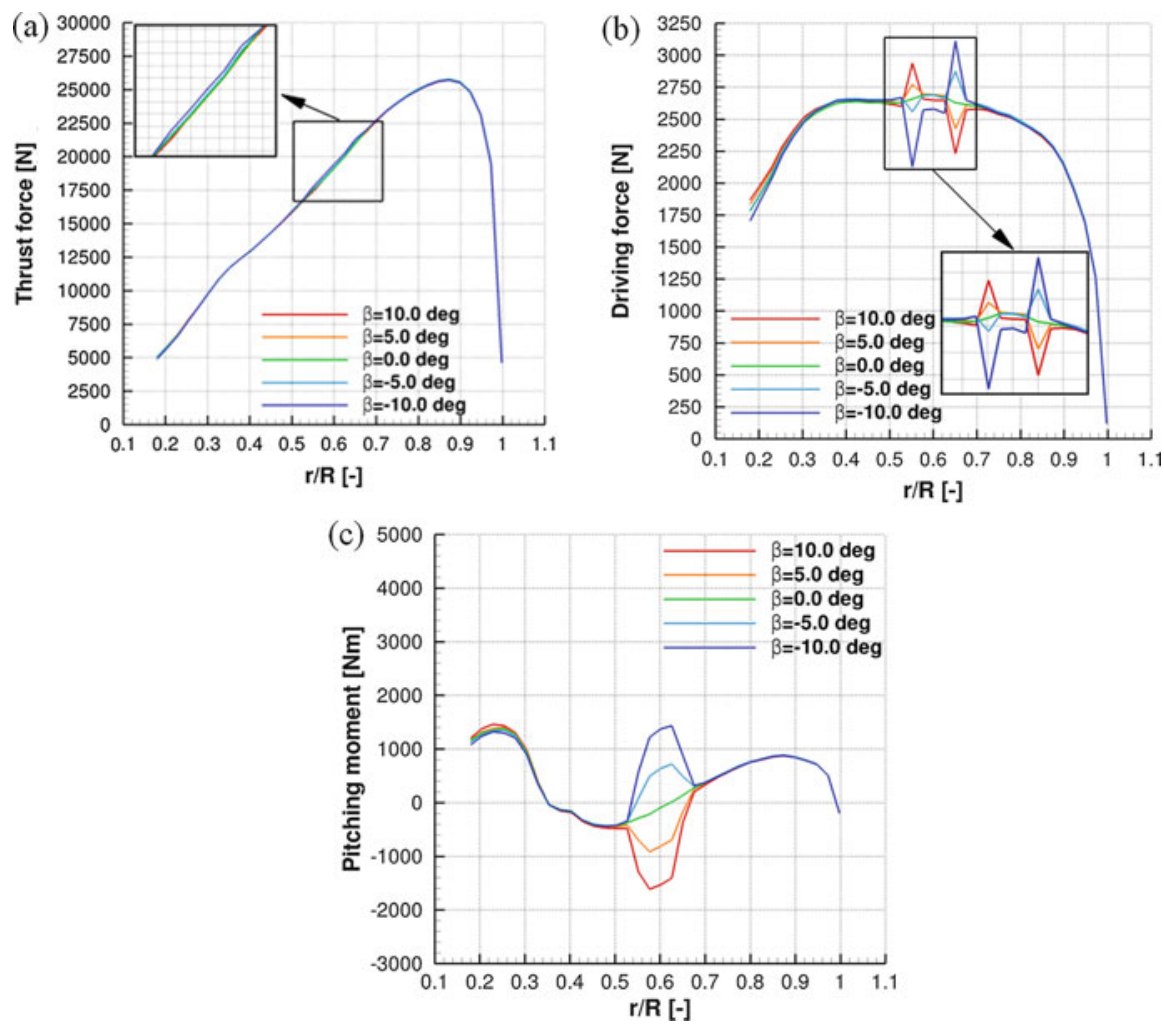

Fig. 7.10 Spanwise distribution of thrust force (a), driving force (b) and pitching moment (c) for DTU blade equipped with LE flap. Flap motion frequency $\mathrm{f}=0.96 \mathrm{~Hz}$ (6 times per revolution)

force coefficient $(\mathrm{CN})$, tangential force coefficient $(\mathrm{CT})$ and pitching moment coefficient $(\mathrm{CM})$ were computed. First, the thrust and driving forces were projected on the normal and tangential directions using local geometrical pitch angle $\alpha$ as:

$$
\begin{aligned}
& F_{N}=T_{F} \cdot \cos (\alpha)+D_{F} \cdot \sin (\alpha) \\
& F_{T}=D_{F} \cdot \cos (\alpha)-T_{F} \cdot \sin (\alpha)
\end{aligned}
$$

The thrust $\left(T_{F}\right)$ and driving $\left(D_{F}\right)$ forces are defined in Fig. 7.11, and were obtained from the surface pressure integration in the middle of the flap with the length of the section in radial direction $\Delta r=2.15 \mathrm{~m}$. Note, that the geometrical pitch angle $\alpha$ is defined in Bak et al. (2013), and is constant i.e. it does not change 


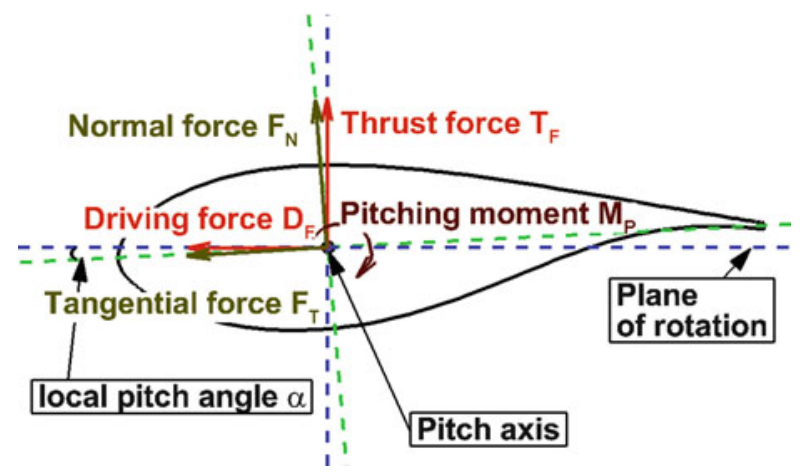

Fig. 7.11 Definition of the normal force, tangential force and pitching moment. Quantities shown in the directions defined as positive

with the flap angle $\beta$. Then, the forces and moment were non-dimensionalized as:

$$
\begin{aligned}
C N & =\frac{F_{N}}{0.5 \rho U^{2} A} \\
C T & =\frac{F_{T}}{0.5 \rho U^{2} A} \\
C M & =\frac{M_{P}}{0.5 \rho U^{2} A c}
\end{aligned}
$$

where $U$ and $A$ are the geometrical local inflow velocity and the local platform area, respectively. The inflow velocity is defined as:

$$
U^{2}=(\Omega r)^{2}+U_{\text {wind }}^{2}
$$

and the platform area is defined as:

$$
A=\Delta r \cdot c
$$

where $c$ is the local chord in the middle of the flap.

The obtained coefficients for both flaps as functions of the flap angle $\beta$ are compared in Fig. 7.12. As can be seen, the trailing edge flap significantly modifies all three non-dimensional coefficients. On the other hand, leading edge flap has the most pronounced effect on the pitching moment coefficient, and almost negligible (as compared to the TE flap) influence on the normal force coefficient. Further, the relative change and slope of the pitching moment coefficient is higher for the trailing edge flap. Finally, both flaps can change the tangential force coefficient, but the TE flap has higher hysteresis loop, as compared to the results for the LE flap. 

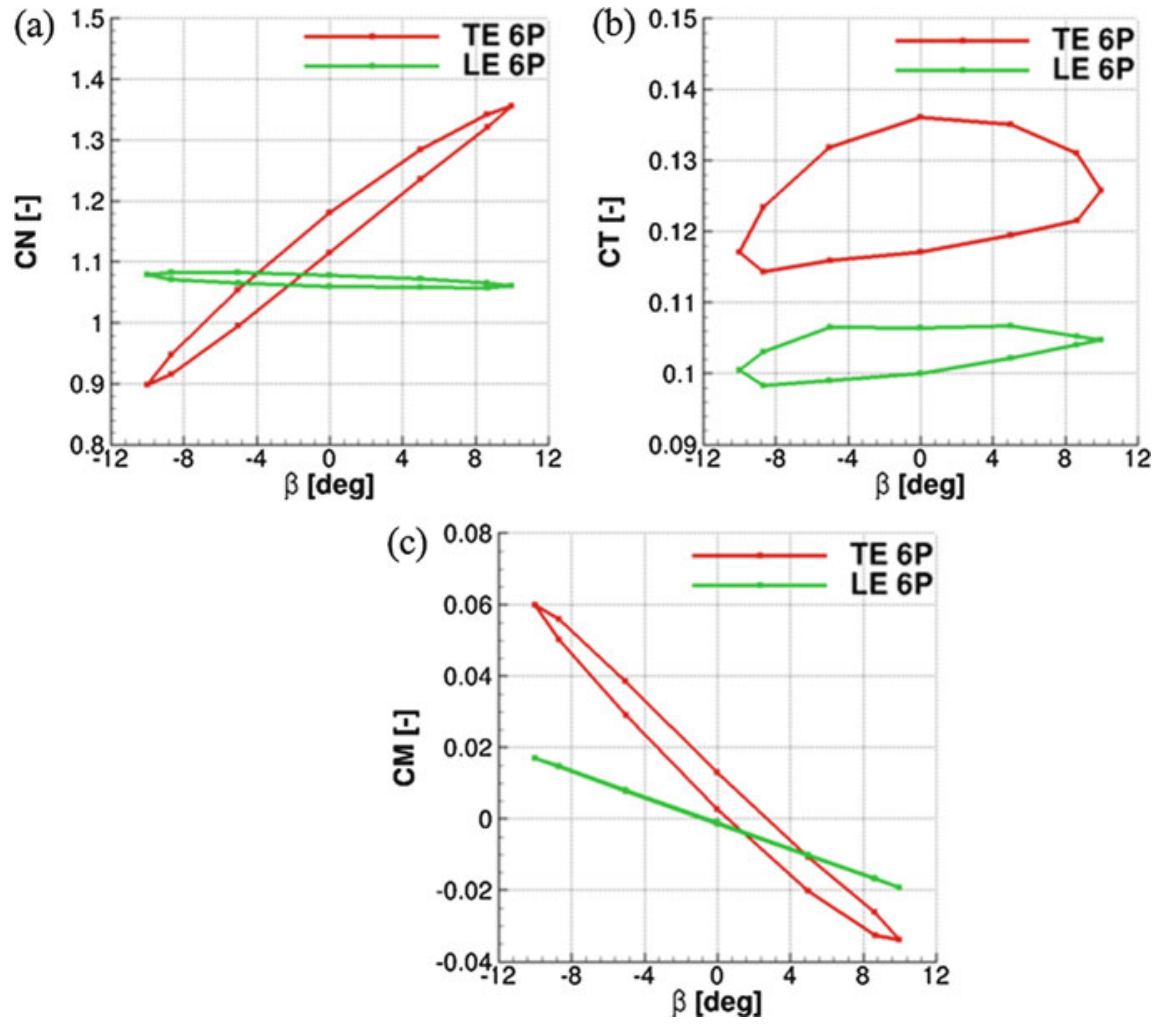

Fig. 7.12 Comparison of the performance of TE and LE flaps based on the non-dimensional coefficients as function of flap deflection angle. (a) Normal force coefficient. (b) Tangential force coefficient. (c) Pitching moment coefficient

\subsection{Summary}

The results showed a significant, but localized effect of the flap deflection on the distribution of the loads. The trailing edge flap can modify both thrust force and pitching moment, whereas trailing edge flap mostly affects the pitching moment. That suggests, that trailing edge flaps can be used to locally change aerodynamic loads on the blades, possibly eliminating the adverse effect of the blade passing in front of the tower. On the other hand the leading edge flap can be used to counter the additional pitching moment created by the deflection of the trailing edge flap.

Acknowledgments Results were obtained using the EPSRC funded ARCHIE-WeSt High Performance Computer (www.archie-west.ac.uk). EPSRC grant no. EP/K000586/1. 
Open Access This chapter is distributed under the terms of the Creative Commons AttributionNonCommercial 4.0 International License (http://creativecommons.org/licenses/by-nc/4.0/), which permits any noncommercial use, duplication, adaptation, distribution and reproduction in any medium or format, as long as you give appropriate credit to the original author(s) and the source, provide a link to the Creative Commons license and indicate if changes were made.

The images or other third party material in this chapter are included in the work's Creative Commons license, unless indicated otherwise in the credit line; if such material is not included in the work's Creative Commons license and the respective action is not permitted by statutory regulation, users will need to obtain permission from the license holder to duplicate, adapt or reproduce the material.

\section{References}

Bak C, Zahle F, Bitsche R et al (2013) The DTU 10-MW reference wind turbine. In: DTU Orbit - The Research Information System. Available via Technical University of Denmark. http://orbit.dtu.dk/files/55645274/The_DTU_10MW_Reference_Turbine_ Christian_Bak.pdf. Accessed 06 Apr 2016

Carrión M, Woodgate M, Steijl et al (2013) Implementation of all-Mach Roe-type schemes in fully implicit CFD solvers - demonstration for wind turbine flows. Int J Numer Methods Fluids 73(8):693-728. doi:10.1002/fld.3818

Carrión M, Steijl R, Woodgate M et al (2014) Computational fluid dynamics analysis of the wake behind the MEXICO rotor in axial flow conditions. Wind Energy 18:1025-1045. doi:10.1002/we.1745

Carrión M, Woodgate M, Steijl R et al (2015) Understanding wind-turbine wake breakdown using computational fluid dynamics. AIAA J 53(3):588-602. doi:10.2514/1.J053196

Dubuc L, Cantariti F, Woodgate M et al (2000) A grid deformation technique for unsteady flow computations. Int J Numer Methods Fluids 32(3):285-311

Eisenstat S, Elman H, Schultz M (1983) Variational iterative methods for nonsymmetric systems of linear equations. Siam J Numer Anal 20:345-357. doi:10.1137/0720023

Gómez-Iradi S, Steijl R, Barakos G (2009) Development and validation of a CFD technique for the aerodynamic analysis of HAWT. J Sol Energy Eng. doi:10.1115/1.3139144

Jameson A (1991) Time dependent calculations using multigrid, with applications to unsteady flows past airfoils and wings. In Abstracts of the 10th computational fluid dynamics conference, fluid dynamics and co-located conferences, AIAA, Honolulu, 24-26 June 1991

Jarkowski M, Woodgate M, Barakos G et al (2013) Towards consistent hybrid overset mesh methods for rotorcraft CFD. Int J Numer Methods Fluids 74(8):543-576. doi:10.1002/fld.3861

Osher S, Chakravarthy S (1983) Upwind schemes and boundary conditions with applications to Euler equations in general geometries. J Comput Phys 50:447-481. doi:10.1016/0021-9991(83)90106-7

Rieper F (2011) A low-Mach number fix for Roe's approximate Riemann solver. J Comput Phys 230(13):5263-5287. doi:10.1016/j.jcp.2011.03.025

Spalart P, Jou W, Strelets M et al (1997) Comments on the feasibility of LES for wings, and on a hybrid RANS/LES approach. In: Liu C, Liu Z (eds) Proceedings of the first AFOSR international conference on DNS/LES, Louisiana, 1997

Steijl R, Barakos G (2008) Sliding mesh algorithm for CFD analysis of helicopter rotor-fuselage aerodynamics. Int J Numer Methods Fluids 58:527-549. doi:10.1002/fld.1757

Steijl R, Barakos G, Badcock K (2006) A framework for CFD analysis of helicopter rotors in hover and forward flight. Int J Numer Methods Fluids 51(18):819-847. doi:10.1002/fld.1086

Van Leer B (1979) Towards the ultimate conservative difference scheme, a second order sequel to Godunov's method. J Comput Phys 32:101-136 